\title{
Proyecto educativo para la estimulación del lenguaje de niños con autismo
}

\author{
Educational project for the stimulation of the language of children with autism \\ Projeto educacional para estimulação da linguagem de crianças com autismo
}

\section{Alejandra Jael Navarro Villa}

alejandrar8@gmail.com

https://orcid.org/0000-0002-5069-4827

Universidad Privada Domingo Savio, Potosí, Bolivia

\section{RESUMEN}

El autismo es una alteración neurológica que afecta la comunicación e interacción social. El diagnóstico e intervención temprana del niño con autismo asegura un mejor desarrollo del lenguaje. En este artículo se presenta, de forma parcial, la propuesta de un proyecto educativo que potencia, coordina e integra el trabajo de todos los profesionales de un Centro de Educación Especial Psicopedagógico en Sucre, Bolivia para estimular el lenguaje de los estudiantes diagnosticados con autismo. Fue una investigación proyectiva, con un diseño de campo. La población fue de 25 estudiantes, de los cuales se escogió una muestra intencional de 7 niños y a sus respectivos padres. También se consideran 4 maestros que atienden, de forma individual, a estos niños en diferentes áreas del desarrollo. Las técnicas para la recolección de los datos fueron la observación no participativa, la entrevista y la encuesta y os instrumentos la guía de observación estructurada, la guía de entrevista y dos cuestionarios.

Palabras clave:

Autismo; estimulación del lenguaje; proyecto educativo; intervención

\begin{abstract}
Autism is a neurological disorder that affects communication and social interaction. Early diagnosis and intervention of the child with autism ensures better language development. This article presents the proposal of an educational project that enhances, coordinates and integrates the work of all the professionals of a Psych pedagogical Special Education Center in Sucre, Bolivia to stimulate the language of students diagnosed with autism. Was a projective investigation, with a field design. The population was 25 students, from which an intentional sample of 7 children and their respective parents was chosen. 4 teachers are also considered who attend, individually, these children in different areas of development. The techniques for data collection were non-participatory observation, the interview and the survey and the instruments the structured observation guide, the interview guide and two questionnaires.
\end{abstract}

Key words:

Autism; language stimulation; educational project; intervention

\section{RESUMO}

O autismo é um distúrbio neurológico que afeta a comunicação e a interação social. O diagnóstico precoce e a intervenção na criança com autismo garantem um melhor desenvolvimento da linguagem. Este artigo apresenta, em parte, a proposta de um projeto educacional que valoriza, coordena e integra o trabalho de todos os profissionais de um Centro de Educação Psicopedagógica Especial em Sucre, Bolívia, para estimular a linguagem de alunos com diagnóstico de autismo. É uma investigação projetiva, com desenho de campo. A população é de 25 alunos, dos quais foi escolhida uma amostra intencional de 7 crianças e seus respectivos pais. Também são considerados 4 professores que atendam, individualmente, essas crianças em diferentes áreas de desenvolvimento. As técnicas de coleta de dados foram a observação não participante, a entrevista e o levantamento e os instrumentos o roteiro de observação estruturado, o roteiro de entrevista e dois questionários.

Palavras-chave:

Autismo; estimulação da linguagem; projeto educacional; intervenção 


\section{INTRODUCCIÓN}

El autismo es un trastorno cuya definición ha evolucionado con el apoyo de los resultados de las investigaciones; desde las publicaciones de Kanner y Asperger en los años 40, fundamentadas en descripciones de individuos con características de personalidad introspectiva (Feinstein, 2016), hasta la definiciones más actuales que lo contempla como una alteración neurológica con características en el comportamiento y la comunicación.

Al respecto cabe citar que en 1979, investigadoras como Wing y Gold estudiaron el autismo con una perspectiva cognitiva y neurobiológica. Estas autoras concluyeron que las personas con autismo presentaban deficiencias en las tres áreas definidas por Kanner y Asperger: (a) reciprocidad social, (b) comunicación verbal y no verbal, (c) capacidad simbólica e imaginativa. Además Wing y Gold identificaron diferentes gradientes o niveles de afectación, por esta razón se considera el autismo como un continuo, de allí surge la denominación de "Trastorno del Espectro del Autismo" (TEA), (Gobierno de España, 2016).

El trastorno del Espectro Autista (TEA) es una alteración neurológica del desarrollo que se manifiesta en los primeros años de vida y se caracteriza, según el Manual Diagnóstico y Estadístico de los Trastornos Mentales de la Asociación Americana de Psiquiatría (DSM-5), por las deficiencias persistentes en la comunicación y en la interacción social en diversos contextos, y por patrones restrictivos y repetitivos de comportamiento, intereses o actividades presentes desde la primera infancia, que limita o impiden el funcionamiento cotidiano (American Psychiatric Association, 2013).

Se puede definir el autismo como un trastorno del neurodesarrollo, que se detecta en edades tempranas, afectando a lo largo de todo el ciclo vital, se caracteriza porque la persona presenta alteraciones en: las relaciones sociales, en la comunicación, lenguaje verbal y no verbal, en la simbolización, imaginación, y en la flexibilidad mental; puede variar de forma cualitativa de una persona a otra. (Borja, 2006; Barthelemy, Fuentes, Howlin, y Van der Gaag, 2008; Brien, 2013 y Uribe, 2015).

La evidencia empírica muestra que la vista es el mejor sentido en el autismo, se conoce que un gran porcentaje de niños con TEA son pensadores visuales o utilizan las áreas del cerebro destinadas al procesamiento visual para resolver tareas; por esta razón si se quiere estimular el lenguaje se deben fundamentar las estrategias en el uso de imágenes (Universidad de Valencia, 2011).

El lenguaje es una de las áreas que presentan mayores alteraciones en el autismo, se presentan graves alteraciones en el desarrollo del lenguaje $y$ en las funciones comunicativas verbales y no verbales.

Las dificultades en la fluidez del habla que pueden presentar los niños autistas son: (a) la fonología o articulación se observa en la pronunciación incorrecta de las palabras; (b) prosodia o entonación caracterizada por una entonación monótona con tono de voz bajo; (c) ecolalia es la repetición de palabras o frases de forma inmediata o diferida; (e) sintaxis se evidencia como la construcción incorrecta de las frases; (f) comprensión y semántica se observa que tienen problemas para entender y transmitir ideas; (g) agnosia auditiva consiste en la dificultad de descodificar el lenguaje verbal y ( $h$ ) lenguaje no verbal inexpresivo caracterizado por la ausencia de gestos. (Rodríguez, 2003; Artigas, 2005; Vélez, 2006).

La estimulación del desarrollo del lenguaje en el niño con autismo es un proceso con tres grandes momentos: el diagnóstico, la orientación y la intervención. Al ser diagnosticados se prepara un plan individualizado, con estrategias adaptadas 
a las necesidades individuales, se pone en práctica el plan y se orienta al núcleo familiar para lograr los mejores resultados.

Esta estimulación involucra varios niveles como el cognitivo, sensorial, perceptivo para llegar a estimular específicamente el área del lenguaje. En consideración, Guerschberg (2008) describe algunos aspectos que se deben tomar en cuenta para estimular el área del lenguaje de estos niños y son las siguientes: la atención, imitación motora, esperar el turno, comunicación intencional, contacto visual, contacto físico - social, entender y escuchar a otros.

La atención de estudiantes con este trastorno es un reto para los docentes y padres de familia, se debe enseñar con las estrategias adecuadas para lograr el procesamiento de la información y el aprendizaje significativo y el desarrollo del lenguaje es de vital importancia para la comunicación de las ideas.

La práctica en el Centro de Educación Especial Psicopedagógico Ciudad Joven "San Juan de Dios" permitió identificar algunas situaciones que pueden atenderse para prestar un mejor servicio y beneficiar a los estudiantes y los maestros. Por ejemplo: (a) las acciones que se desarrollan en el centro no tienen articulación, son desarrolladas de manera independiente por cada maestro; (b) los maestros no registran sistemáticamente las acciones que ejecutan para la estimulación del lenguaje de los niños con autismo; (c) los maestros aplican actividades para estimular el área del lenguaje pero no atienden todas las variaciones; y (d) el contacto con la familia es muy poco, los padres desconocen las actividades de intervención y sus efectos.

De acuerdo con lo planteado anteriormente se formula el problema de investigación: ¿Cuáles son las características de un proyecto educativo que permita estimular lenguaje de niños con autismo del Centro de Educación Especial Psicopedagógico
Ciudad Joven "San Juan de Dios" en la ciudad de Sucre, Bolivia? Asimismo el objetivo fue: Proponer un proyecto educativo para fortalecer la estimulación del lenguaje de niños con autismo del Centro de Educación Especial Psicopedagógico Ciudad Joven "San Juan de Dios" en Sucre, Bolivia.

\section{MÉTODO}

Investigación proyectiva en la cual se diseñó un proyecto educativo para atender la estimulación del lenguaje en niños con autismo. El enfoque es mixto porque se obtienen y procesan datos de forma cualitativa y cuantitativa, el diseño es de campo, pues los datos se recolectaron en el ambiente educativo natural en el cual se a tiende a los niños con autismo.

El contexto en el cual se desarrolló la investigación es el Centro de Educación Psicopedagógico "Ciudad Joven San Juan de Dios" ubicado en la ciudad de Sucre, en Bolivia. Este centro atiende de forma integral a una población de 200 estudiantes, entre niños y adolescentes, que presentan diferentes alteraciones psíquicas y físicas. Tiene como objetivo conseguir la recuperación-rehabilitación integral y lograr la inclusión del paciente al núcleo familiar, laboral y social. Para ello, cuenta con un equipo profesional multidisciplinario para brindar atención médica y de carácter social.

En este centro existe una población de 25 estudiantes con diagnóstico de autismo, de los cuales se escogió una muestra de 7 niños con edades comprendidas entre 6 y 8 años y niveles similares de autismo y a sus respectivos padres. También se consideran 4 maestros que atienden, de forma individual, a estos niños en diferentes áreas del desarrollo.

Las técnicas para la recolección de los datos fueron la observación no participativa, la entrevista y la encuesta. Los instrumentos estuvieron 
constituidos por: (a) la guía de observación estructurada con 8 ítems que capta la aplicación de estrategias para la estimulación del lenguaje de los niños con autismo por parte de los docentes; (b) La guía de entrevista aplicada a la terapista del lenguaje y a la directora, constituida por 13 ítems, permitió comprender la situación de la estimulación del lenguaje, de acuerdo a la percepción de la especialista y el directivo; (c) dos cuestionarios, de
13 ítems cada uno, se aplicó uno a los docentes y otro a los padres de los niños de la muestra, con el propósito de recolectar información acerca de la estimulación del lenguaje de los niños.

La variable dependiente de la investigación es la estimulación del lenguaje en niños con autismo y su operacionalización con tres dimensiones se observa en el Cuadro 1.

Cuadro 1. Operacionalización de la variable.

\begin{tabular}{|c|c|c|c|}
\hline Variable Dependiente & Definición Operacional & Dimensiones & Indicadores \\
\hline $\begin{array}{l}\text { Estimulación del } \\
\text { lenguaje de niños } \\
\text { con autismo }\end{array}$ & $\begin{array}{l}\text { Es un proceso } \\
\text { que contempla el } \\
\text { diagnóstico, orientación } \\
\text { e intervención, para } \\
\text { determinar acciones } \\
\text { dirigidas a la ampliación, } \\
\text { adecuación y uso del } \\
\text { lenguaje mediante la } \\
\text { aplicación de técnicas } \\
\text { adecuadas que posibilite } \\
\text { al niño un aprendizaje } \\
\text { funcional del lenguaje. }\end{array}$ & Intervención & $\begin{array}{l}\text { Aplica pruebas diagnosticas } \\
\text { Se elabora un plan individualizado } \\
\text { Realiza entrevista a los padres de } \\
\text { familia } \\
\text { Realiza devolución de los resultados } \\
\text { Realiza orientación sobre cómo debe } \\
\text { intervenir en el área del Lenguaje } \\
\text { Ejecuta técnicas para la ampliación } \\
\text { del lenguaje } \\
\text { Ejecuta técnicas para la adecuación } \\
\text { del lenguaje } \\
\text { Ejecuta técnicas para mejorar el uso } \\
\text { del lenguaje } \\
\text { Realiza seguimiento del desarrollo del } \\
\text { lenguaje }\end{array}$ \\
\hline
\end{tabular}

\section{RESULTADOS}

Los resultados se presentan de acuerdo a los instrumentos utilizados, se discriminan las tres dimensiones de la variable: diagnóstico, orientación e intervención.

\section{Guía de entrevista con la directora del centro} Dimensión diagnóstico: El diagnóstico lo realiza una psicóloga en consulta externa al centro. Se aplican pruebas como la escala M-chat a los niños y entrevistas a los padres.

Dimensión orientación: No existe una orientación programada para los padres, al inicio de la atención se hace una entrevista.

Dimensión intervención: Los docentes no tienen mucha experiencia en el trato de niños con autismo. Los maestros elaboran un plan individualizado para cada niño de acuerdo a sus necesidades. Para aplicar planes para atender el desarrollo del 
lenguaje es necesario que los docentes conozcan el nivel del coeficiente intelectual, el desarrollo evolutivo, el grado del lenguaje-comunicación, las habilidades y las aptitudes, con el objetivo de responder a sus necesidades específicas. No existen programas para estimular el área de lenguaje.

\section{Cuestionario dirigido a los maestros}

Dimensión diagnóstico: tres de los cuatro maestros aplican pruebas diagnósticas para evaluar el lenguaje.

Dimensión orientación: Tres de cuatro maestros realizan entrevistas con los padres de familia. Solo un maestro informa de los resultados a los padres y los orienta acerca del desarrollo del lenguaje.

Dimensión intervención: La mitad de los maestros aplican estrategias específicas para: articular los sonidos, estimular la ampliación del vocabulario, adecuar el tono de voz, mejorar el contacto visual. Solo un maestro realiza actividades para disminuir la repetición de palabras y mejorar las expresiones faciales.

Los cuatro maestros indican que no tuvieron avances significativos en el área de lenguaje y consideran importante actualizarse en estrategias para atender esta área.

\section{Cuestionario dirigido a los padres de familia}

Dimensión diagnóstico: al inicio aplicaron unas pruebas.

Dimensión orientación: 5 padres indican que no les informaron los resultados de las pruebas, 2 padres manifiestan que si les dieron resultados acerca de las características del lenguaje de sus hijos. No reciben orientación acerca de su papel para el desarrollo del lenguaje de su hijo.

\section{Entrevista a la terapista del lenguaje}

Dimensión diagnóstico: a los estudiantes con el diagnóstico de autismo se les aplica al inicio de gestión, algunos instrumentos estandarizados especialmentela escala de M-chat paradiagnosticar dificultades en el área del lenguaje y así realizar la intervención correspondiente tomando en cuenta el tipo y el grado de discapacidad.

Dimensión orientación: Después de realizar el diagnóstico, la terapeuta del lenguaje aplica una entrevista dirigida a los padres de familia tomando en cuenta algunos aspectos como el social, económico, familiar, sin embargo, la terapeuta considera que la intervención es entre terapeuta y paciente sin involucrar a los padres de familia.

Dimensión intervención: Para la intervención correspondiente la terapista utiliza el sistema aumentativo de comunicación para la estimulación del lenguaje y aplica diferentes estrategias tanto para articulación de palabras donde están las actividades de praxias y sonidos articulatorios, para la ampliación de palabras como fichas con imágenes, para las ecolalias actividades como las rimas ,para adecuar el tono de voz están las actividades de relajación y canciones, para mejorar las expresiones faciales se realizan actividades con títeres y para mejorar el contacto visual está la técnica del espejo.

Las estrategias que aplica la terapista del lenguaje son adecuadas para estimular el área del lenguaje verbal y no verbal pero también se debe hacer uso de diferentes modalidades que favorezcan la atención conjunta a través de sistemas de ayudas y apoyos como claves visuales, paneles con pictogramas, fotos y palabras escritas con el fin de responder a las necesidades de cada estudiante con autismo.

\section{Guía de observación}

Dimensión intervención: Se considera la observación de las estrategias y acciones para el desarrollo del lenguaje. (Ver gráfico 1) 


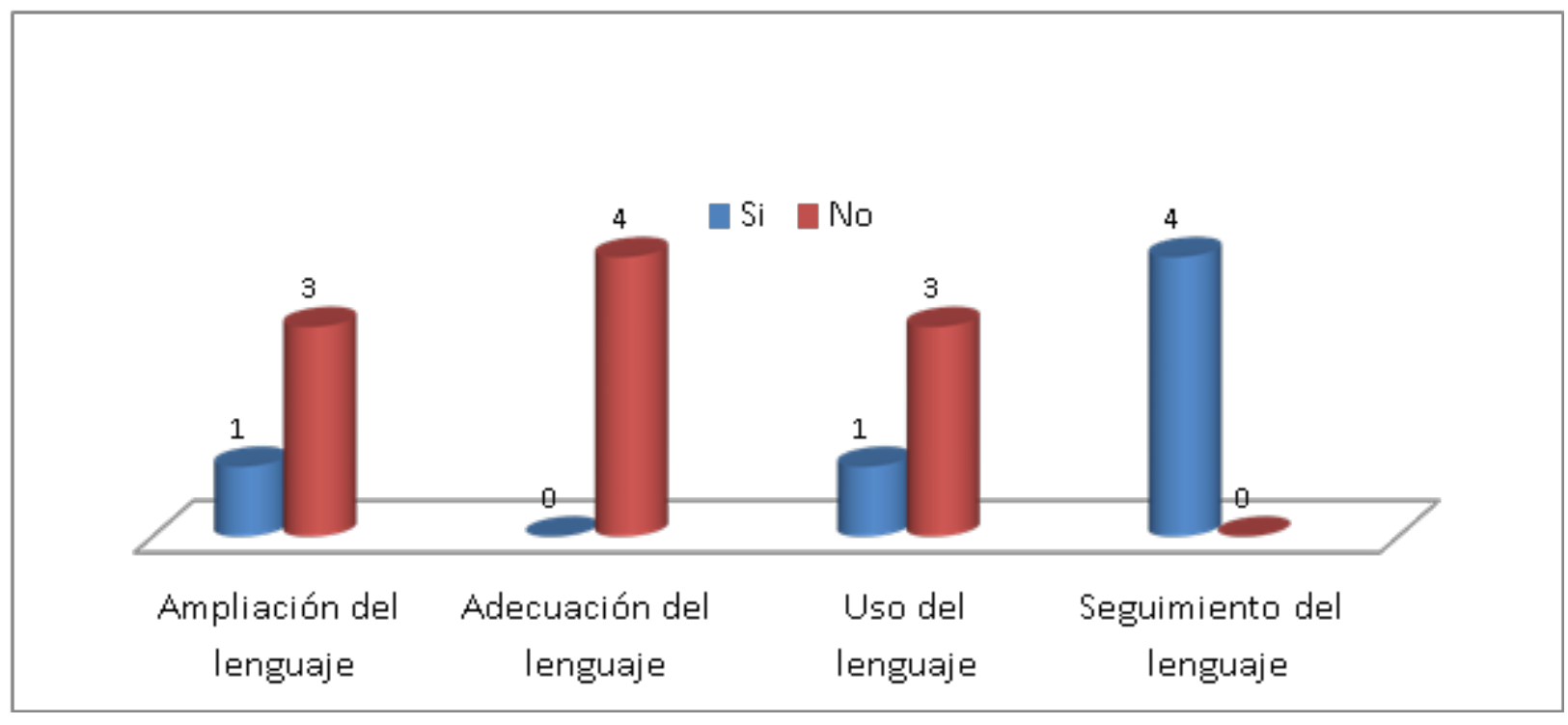

Gráfico 1. Intervención del lenguaje.

Solo uno de los maestros aplica actividades para la ampliación y uso del lenguaje, ninguno adecua el lenguaje a las características del estudiante; todos realizan seguimiento del lenguaje. No realizan actividades para la adecuación del tono de voz.

Con base en los resultados obtenidos en el diagnóstico se diseña el proyecto educativo del Centro de Educación Especial para la estimulación del lenguaje de niños con autismo.

Se escoge el proyecto educativo porque es el instrumento que permite abordar los problemas, alcanzar los objetivos planteados y evaluar los resultados con la participación de todos los involucrados en la situación que se diagnostica (Alvarado, 2005; Capaletti, 2008).

Los niños con autismo precisan de una intervención permanente y articulada, entre quienes intervienen en esta estimulación como la terapeuta del lenguaje, el fonoaudiólogo, el maestro y el psicopedagogo.

Considerando que la siguiente gestión el centro pretende mejorar la atención a personas con autismo, incluyendo más áreas de trabajo y profesionales, teniendo en cuenta las necesidades encontradas, es oportuno plantear la propuesta del proyecto educativo para la estimulación del lenguaje de los estudiantes con autismo.

\section{PROPUESTA}

Proyecto educativo para fortalecer la estimulación del lenguaje en niños con autismo

\section{Aprendo a hablar a través de los pictogramas}

Contexto: Centro de Educación Especial Psicopedagógico “Ciudad Joven San Juan de Dios”. Fundamentación: El proyecto educativo tiene sus bases en los principios organizadores de la didáctica y la lingüística, iniciar con los contenidos más simples hasta los más complejos y considerar el desarrollo aptitudes visuales, auditivas y pragmáticas.

Objetivo General: Generar acciones institucionales encaminadas al desarrollo de actividades para la estimulación del lenguaje de niños con autismo del Centro de Educación Especial Psicopedagógico "San Juan de Dios" de la ciudad de Sucre. 


\section{Objetivos específicos}

- Elaborartalleresdeactualización paramaestros con el fin de fortalecer las competencias en cuanto a la estimulación del lenguaje de niños con autismo.

- Diseñar un plan de intervención al nivel de desarrollo de niños con autismo para la estimulación del lenguaje de manera individual.

- Organizar espacios que posibiliten la orientación a padres de familia en cuanto a la estimulación del lenguaje.
- Realizar un análisis multidisciplinario que contribuya a fortalecer la estimulación del lenguaje de los niños con autismo.

Talleres dirigidos a docentes: La responsable de aplicar los talleres a maestros será la terapeuta del lenguaje o la psicopedagoga, los cuales tendrán una duración de cuatro meses.

Taller 1. Fundamentos teóricos del autismo.

Nombre del taller: Presentación de la propuesta y Fundamentos teóricos del autismo

Participantes: Los docentes del centro de educación especial.

Objetivo: Socializar la propuesta. Desarrollar con los participantes competencias teórico - prácticas para comprender y atender a la población con autismo.

Metodología: Activa participativa

\begin{tabular}{|c|c|c|c|}
\hline Fase & Actividades o temas a tratar & Materiales & Tiempo \\
\hline Inicio & $\begin{array}{l}\text { Se inicia con una dinámica de presentación de la propuesta, } \\
\text { fundamentos y alcance. Se realiza una actividad de inicio a los } \\
\text { contenidos acerca del autismo, mediante fotografías y dibujos para } \\
\text { dar una anécdota de un niño con autismo }\end{array}$ & $\begin{array}{c}\text { Fotografías o } \\
\text { dibujos }\end{array}$ & $15^{\prime}$ \\
\hline \multirow[t]{2}{*}{ Central } & $\begin{array}{l}\text { En principio se mostrará un video acerca de las características de niños } \\
\text { con autismo y se les preguntará acerca del video. Posteriormente se } \\
\text { realizará un socio drama que nos permitirá mostrar elementos para } \\
\text { el análisis, sin embargo las personas que van a hacer el socio drama } \\
\text { dialogarán sobre lo que conocen del tema, cómo lo viven, cómo } \\
\text { lo entienden y a partir de ello se explicará la definición y tipos de } \\
\text { autismo. }\end{array}$ & $\begin{array}{c}\text { Proyector } \\
\text { multimedia y } \\
\text { video }\end{array}$ & 1 hora \\
\hline & Receso & & $10 \mathrm{~min}$ \\
\hline Final & $\begin{array}{l}\text { Se les solicita a los docentes que respondan a las siguientes pregun- } \\
\text { tas: ¿Qué he aprendido? } \\
\text { ¿Qué voy a aplicar en mi trabajo? ¿Qué queda pendiente? ¿Qué puedo } \\
\text { aportar? }\end{array}$ & $\begin{array}{l}\text { Papel y } \\
\text { lápices }\end{array}$ & $30 \mathrm{~min}$ \\
\hline
\end{tabular}


Taller 2. Comunicación.

Nombre del taller: La comunicación de los niños con autismo

Participantes: Docentes del centro de educación especial

Objetivo: Analizar aspectos que contribuyan al desarrollo del lenguaje de los niños con autismo para que los maestros adquieran conocimientos y estrategias para su aplicación. Comprender el papel de la familia en el desarrollo del lenguaje

Metodología: Activa participativa.

\begin{tabular}{|c|c|c|c|}
\hline Fase & Actividades o temas a tratar & Materiales & Tiempo \\
\hline Inicio & $\begin{array}{l}\text { Al inicio se realizará una dinámica que titula fotografías con } \\
\text { preguntas para retroalimentar la información anteriormente } \\
\text { expuesta y así poder entrar a la temática de comunicación de } \\
\text { niños con autismo. }\end{array}$ & $\begin{array}{c}\text { Fotografías o } \\
\text { dibujos }\end{array}$ & $20^{\prime}$ \\
\hline \multirow[t]{2}{*}{ Central } & $\begin{array}{l}\text { En el taller se desarrollará los siguientes contenidos: La } \\
\text { comunicación y el desarrollo del lenguaje de los niños con } \\
\text { autismo; papel de la familia en la estimulación del lenguaje. } \\
\text { A continuación a través de recortes con imágenes se explicará } \\
\text { acerca de la comunicación- lenguaje de los niños con autismo. } \\
\text { Posteriormente se realizará una dinámica de Collage de un caso } \\
\text { de un niño con autismo y se hará una explicación divertida con la } \\
\text { dinámica cambio de roles. } \\
\text { Reflexión sobre la influencia de la familia en el desarrollo del } \\
\text { lenguaje. }\end{array}$ & $\begin{array}{l}\text { Proyector } \\
\text { multimedia } \\
\text { recortes con } \\
\text { imágenes y } \\
\text { materiales } \\
\text { como } \\
\text { praxias, } \\
\text { imágenes } \\
\text { con su } \\
\text { respectiva } \\
\text { oración y } \\
\text { música }\end{array}$ & 1 hora \\
\hline & Receso & & $10 \mathrm{~min}$ \\
\hline Final & $\begin{array}{l}\text { Se realizará la evaluación con una dinámica que se titula el } \\
\text { muñeco para evaluar el conocimiento acerca de las características } \\
\text { de la comunicación y el desarrollo del lenguaje de la población } \\
\text { con autismo. }\end{array}$ & $\begin{array}{l}\text { Un muñeco, } \\
\text { tarjetas de } \\
\text { colores y } \\
\text { marcadores }\end{array}$ & $30 \mathrm{~min}$ \\
\hline
\end{tabular}


Taller 3. Sistemas de comunicación.

Nombre del taller: Sistemas alternativa/aumentativa de comunicación

Participantes: Docentes del centro de educación especial.

Objetivo: Desarrollar habilidades en los maestros para la aplicación de estrategias y estimular el área del lenguaje de los niños con autismo de acuerdo al tipo y al grado de discapacidad

Metodología: Activa participativa.

\begin{tabular}{|c|c|c|c|}
\hline Fase & Actividades o temas a tratar & Materiales & Tiempo \\
\hline Inicio & $\begin{array}{l}\text { Formar grupos de } 3 \text { integrantes, se facilitará a cada grupo cuentos con } \\
\text { pictogramas y rompecabezas con preguntas: ¿Para qué cree que sirve } \\
\text { las ayudas visuales? ¿Para usted es importante utilizar las ayudas } \\
\text { visuales con los } \\
\text { niños con autismo? ¿Por qué? }\end{array}$ & $\begin{array}{l}\text { Marcador y } \\
\text { música }\end{array}$ & $20^{\prime}$ \\
\hline \multirow[t]{2}{*}{ Central } & $\begin{array}{l}\text { En el taller se desarrollará los siguientes contenidos: Pictograma- } \\
\text { Lenguaje bimodal- Sistemas de comunicación por intercambio de } \\
\text { imágenes. } \\
\text { Seguidamente se realizará una dinámica que titula Abejitas } \\
\text { (cuchicheo, buzz buzz) }\end{array}$ & $\begin{array}{l}\text { Proyector } \\
\text { multimedia } \\
\text { materiales } \\
\text { didácticos y } \\
\text { tarjetas }\end{array}$ & 1 hora \\
\hline & Receso & & $10 \mathrm{~min}$ \\
\hline Final & $\begin{array}{l}\text { Se les solicita a los docentes que respondan a las siguientes preguntas: } \\
\text { ¿En su trabajo que estrategias utilizaría para estimular el área del } \\
\text { lenguaje de los niños con autismo? ¿Según usted qué ventajas tiene } \\
\text { la utilización de sistemas aumentativos en la comunicación? }\end{array}$ & $\begin{array}{l}\text { Hojas y } \\
\text { lápices }\end{array}$ & $30 \mathrm{~min}$ \\
\hline
\end{tabular}

Taller 4. Estimulación de lenguaje.

Nombre del taller: Estimulación del lenguaje verbal y no verbal de niños con autismo

Participantes: Docentes del centro de educación especial.

Objetivo: Brindar a los participantes conceptos y procedimientos sobre la estimulación del lenguaje verbal y no verbal para su aplicación en estudiantes con autismo de acuerdo al tipo y al grado de discapacidad que presentan.

Metodología: Activa participativa.

\begin{tabular}{|c|c|c|c|}
\hline Fase & Actividades o temas a tratar & Materiales & Tiempo \\
\hline Inicio & $\begin{array}{l}\text { Para poder explicar la estimulación del lenguaje no verbal de niños } \\
\text { con autismo se comenzará con una dinámica. Los participantes } \\
\text { forman un círculo, y cada uno con diferentes emociones dirá se murió } \\
\text { chicho, llorando, molesto, sorprendido, alegre y asustado. Y después se } \\
\text { explicará cómo se sienten los niños con autismo al no saber expresar } \\
\text { e identificar las emociones o las expresiones faciales de los demás. }\end{array}$ & $\begin{array}{l}\text { Recursos } \\
\text { humanos }\end{array}$ & $20^{\prime}$ \\
\hline \multirow[t]{2}{*}{ Central } & $\begin{array}{l}\text { En el taller se desarrollarán los siguientes contenidos: Definición } \\
\text { de estimulación del lenguaje verbal y no verbal y los aspectos para } \\
\text { estimular el área del lenguaje no verbal y verbal, seguidamente se } \\
\text { realizará la dinámica Philips } 66\end{array}$ & $\begin{array}{l}\text { Proyector } \\
\text { multimedia }\end{array}$ & 1 hora \\
\hline & Receso & & $10 \mathrm{~min}$ \\
\hline Final & $\begin{array}{l}\text { Finalmente se repartirán hojas y lápices donde se les pedirá que } \\
\text { respondan lo siguiente: ¿Qué he aprendido? ¿Qué voy a aplicar en mi } \\
\text { trabajo? ¿Qué queda pendiente? }\end{array}$ & $\begin{array}{l}\text { Papel y } \\
\text { lápices }\end{array}$ & $30 \mathrm{~min}$ \\
\hline
\end{tabular}


Taller 5. Ampliación, adecuación y uso del lenguaje.

Nombre del taller: Fortalecimiento de la ampliación, la adecuación y el uso del lenguaje

Participantes: Docentes del centro de educación especial.

Objetivo: Brindar a los participantes conceptos y estrategias psicopedagógicas para estimular el área del lenguaje de niños con autismo para que la población adquiera un aprendizaje funcional.

Metodología: Activa participativa.

\begin{tabular}{|c|c|c|c|}
\hline Fase & Actividades o temas a tratar & Materiales & Tiempo \\
\hline Inicio & $\begin{array}{l}\text { Los participantes forman un doble círculo, uno interno mirando } \\
\text { hacia fuera y otro externo hacia dentro. Los dos círculos se } \\
\text { mueven inversamente al ritmo de la música. Cuando la música } \\
\text { se para, deben conversar con la persona que les quede enfrente. }\end{array}$ & Música & $40^{\prime}$ \\
\hline \multirow[t]{2}{*}{ Central } & $\begin{array}{l}\text { En el taller se desarrollará los siguientes contenidos: La ampliación } \\
\text { de la articulación y vocabulario. La adecuación del tono de voz. La } \\
\text { ampliación del contacto visual, las expresiones faciales y disminuir } \\
\text { las ecolalias Después de exponer se realizará una dinámica que } \\
\text { titula estudio de casos, donde se formará grupos para que cada } \\
\text { grupo exponga a través de socio drama y se llegue } \\
\text { a una conclusión. }\end{array}$ & $\begin{array}{l}\text { Video, proyector } \\
\text { multimedia, } \\
\text { papel bond } \\
\text { tamaño, pliego, } \\
\text { fotografías, } \\
\text { documentales, } \\
\text { papel de colores, } \\
\text { imágenes } \\
\text { cinta aislante, } \\
\text { pegamento y } \\
\text { tijera }\end{array}$ & 1 hora \\
\hline & Receso & & $10 \mathrm{~min}$ \\
\hline Final & $\begin{array}{l}\text { Se les solicita a los docentes que respondan a las siguientes } \\
\text { preguntas ¿Qué he aprendido? ¿Qué voy a aplicar en mi trabajo? } \\
\text { ¿Qué queda pendiente? ¿Qué puedo aportar? }\end{array}$ & Papel y lápices & $20 \mathrm{~min}$ \\
\hline
\end{tabular}

Equipo multidisciplinario: Estará formado por un grupo de profesionales de diferentes disciplinas que trabajan con la población de autismo. Estas reuniones se ejecutaran una vez a la semana, donde uno de ellos es responsable del trabajo que se lleva a cabo. A continuación se enunciarán algunos aspectos para la organización de las reuniones de trabajo.

Para ello, se preparará una agenda de trabajo, en la cual, estas reuniones del equipo multidisciplinario responderán a motivos concretos como:

- La reunión comenzará del equipo multidisciplinario antes del encuentro físico con los participantes, ya que es importante que se conozcan previamente las líneas de acción como los talleres y el plan individualizado.

- Se realizará una intervención de equipo multidisciplinario, que consiste en socializar casos de niños con autismo para que cada especialista dé su punto vista con la finalidad de proporcionar otras estrategias de intervención para el paciente.

- Estas reuniones que serán para la socialización se realizaran en el transcurso de un año. Una vez culminado el período escolar se evaluarán los resultados para ajustar el proyecto educativo. 


\section{CONCLUSIONES}

El diagnóstico del niño, antes de incorporarse al centro, se realiza con la aplicación de pruebas estandarizadas, generalmente se utiliza la escala M- chat. Al ser diagnosticado con autismo se incorpora en el grupo de estudiantes con esta condición, pero no se discriminan todas las características individuales de cada uno. Una vez en el centro se realizan entrevistas con los padres, para recabar información acerca de las condiciones de salud y comportamiento de su hijo.

La intervención que realizan los maestros para desarrollar el lenguaje de los estudiantes con autismo presentan carencias ya que no atienden con actividades específicas todas las áreas del desarrollo del lenguaje.

Los padres de los niños con autismo no se sienten orientados para colaborar con el desarrollo del lenguaje de sus hijos.

El proyecto educativo para atender las necesidades diagnosticadas está constituido por talleres dirigido a la actualización del personal docente con estrategias específicas para el desarrollo del lenguaje. Actividades con los padres para potenciar su papel como colaboradores en el desarrollo del lenguaje de su hijo con autismo.

\section{REFERENCIAS}

American Psychiatric Association. (2013). Diagnostic and Statistical Manual of Mental Disorders. DSM-5 (5a ed.). EUA: Autor

Artigas, J. (2005). El lenguaje en los trastornos autistas. Revista neuronal de Perú Barcelona: Ars Médica

Barthélemy, C.; Fuentes, J.; Howlin, P.; Van der Gaag, R. (2008). Persons with Autism Spectrum Disorders- Identification, Understanding, Intervention. Bruselas: Autisme Europe
Borja, E. (2006). Guía de uso para el profesorado para la práctica educativa con niños con autismo y TGD. Curriculum y materiales didácticos, Argentina: Paidós

Brien, E. (2013). Guía para la atención educativa de niños y jóvenes con Trastorno del Espectro Autista, Lima: Grat

Crespo, C., García, L., Coria, G., Carrillo, P., Hernández, M., y Manzo, J. (2016). Mejora de las habilidades motoras y cognitivas de niños con autismo después de un periodo prolongado de juego con deportes virtuales. Neurobiología. Revista electrónica, 7

Feinstein, A. (2016) Historia del autismo. Conversaciones con los pioneros. Mercedes Belinchón Carmona y Javier Muñoz Bravo (Trads.). España: Editores Autismo Ávila

Gobierno de España, Ministerio de Sanidad servicios Sociales e Igualdad. (2016). Guía de y profesores y educadores de alumnos con autismo ( $4^{a}$. ed). Federación de Autismo Castilla y León. https://autismocastillayleon.com/wp-content/ uploads/2016/06/guia_para_profesores_y_ educadores_de_alumnos_con_autismo4.pdf

Guerschberg, M. (2008). Soluciones pedagógicas para el autismo. Argentina: Landeira

Rodríguez. (2003). Dificultades del lenguaje, colaboración e inclusión educativa.

Universidad de Valencia. (2011). Pictogram Room. Guía para padres y educadores. España: AutorFundación Orange. Recuperado de https:// ahedysia.org/guias-pdf/GuiaPictogramRoom. pdf

Uribe, A. (2015). Protocolo clínico para el diagnóstico, tratamiento y ruta de atención integral de niños y niñas con Trastorno de Espectro Autista. Instituto de Evaluación Tecnológica de Salud, Perú: Paidós

Vélez, M. (2006). Orientaciones pedagógicas para la atención educativa a estudiantes con autismo. Bogotá: Euned 